\title{
Audience in Language Teaching and Learning
}

Donna Starks

This article reports on a case study of a technique aimed to increase the pragmatic competence of adult learners of English as a foreign or second language. In this study students are exposed to real audiences in authentic settings. The results show that students learned the subtle effect cultural and social factors can have on a speech event in a way that is difficult to recreate in a classroom setting.

For learners of English, knowledge of and control over the grammatical and pragmatic rules of the language are necessary for effective communication outside the classroom. In many ESL/EFL classrooms, grammatical competence is often highlighted, while pragmatic aspects of language, be they socio-cultural, strategic or discoursal, are often largely ignored despite the well-known fact that intercultural miscommunication is often the result of a lack of pragmatic knowledge and the control of that knowledge. (Bardovi-Harlig, Hartford, Mahan-Taylor, Morgan, \& Reynolds, 1991 pp. 4-5)

This article describes a task-based project designed to increase the grammatical and pragmatic competence of upper-intermediate language learners. The project aims to develop the students' pragmatic knowledge by focusing on style differences determined by factors such as audience and setting. Upperintermediate foreign language learners interact with real audiences in a controlled setting. Students are each given a "real" audience so that through active learning they understand the effect audience has on communication. Because of the large number of factors involved in pragmatic knowledge, several limitations are placed on the tasks. These include limiting the type of transaction (e.g., interview), giving the students the role of addressor (e.g., asking prepared questions), and having them negotiate the setting (e.g., where and when) with the aim that the students achieve both a knowledge of, and control over, a set of speech events that may be applied to a number of different settings and audiences. The students were asked to conduct two similar projects. When learners interact in similar transactions, they learn how to use prior knowledge to help them interact in other speech events.

The project is similar in design to a research project conducted by Vincent (1990) in which students were directed to write for a particular audience with a particular purpose. In Vincent's project, the students worked with the teacher to write a letter of request and prepare for a visit to Shell Petroleum. 
The students subsequently wrote up aspects of their visit (e.g., interview, video presentation) for publication in the company magazine. This study differs from Vincent's in that the teacher acts only as a facilitator. Here students make the initial contacts and engage in individual learning rather than group projects. Learning and communication are viewed as "a two-way process where interlocutors negotiate and create meaning based on their joint input and interpretation of things" (Crawford 1990, p. 49). The teacher observes but does not participate actively in the communication process.

\section{The Students}

The project involved 18 adult EFL upper-intermediate students. All were Japanese and studying English at a residential tertiary level college in New Zealand. All had learned English in high school from nonnative speakers of English. The majority had spent two years in New Zealand but had had relatively little contact with native speakers during that time. Three of the students had only recently arrived in New Zealand. In all cases, entrance tests showed the students' grammatical competence to be far greater than their pragmatic competence.

\section{The Project}

The project was the basis for a Community English course. The class met four hours per week for 14 weeks. Students worked for two hours per week in the classroom and spent the other two hours in the computer room on writing tasks (e.g., preparing interview questions, writing letters, and preparing their reports).

The project was divided into two modules. In both modules the students were asked to conduct a tape-recorded interview and submit a written report. In both cases the setting was formal and the interviewees were not known personally to the students. In the first module the students interviewed a person with whom they had had no previous contact. Here students were asked to arrange an interview with a nonacademic staff member (e.g., custodian, secretary, gardener, registrar) of the residential college about his or her occupation. In the second module the students contacted a community organization or club in which they had a personal interest (e.g., the jazz society, fencing society, antique car society, motor car society). The students had had no prior contact with the group or organization and did not know the name of the person they were to contact.

The interviewees were not contacted in advance by the teacher, nor were the students provided with the interviewees' names or addresses. On completion of their interviews, the students wrote thank-you letters to their interviewees. The completed report was later sent with a covering letter to 
the interviewee. The tasks allowed the teacher to remain a facilitator and the students to be active participants from the beginning to the end of the project.

\section{The Process}

The project created authentic situations requiring follow-up letters and in some cases phone calls. At the beginning of each class students presented a one-or two-minute summary statement of their project status. Any problems were addressed at that time. The discussion enabled all students to be aware of the range of possible and appropriate responses. All worked at their own speed and according to their own audience-based task. Because of the similarities between the projects, the students could work together, yet complete individual tasks. They were encouraged to use one another's work as models. Those who had written follow-up letters and made phone calls in Module One helped others experiencing similar problems in Module Two, thereby shifting the onus from the teacher to the students.

\section{Tasks}

\section{Written Tasks}

Communicative competence involves both written and oral competence. The majority of the written tasks in the two modules involved teaching the students an appropriate procedure for contacting a potential interviewee (e.g., writing letters of request, follow-up letters, and letters of acknowledgement) conducting an interview (e.g., preparing questions, lead-in statements) and writing the results of the interview in the form of a report. The tasks focused on accuracy, style, and appropriateness. Discussion centered around stylistic differences as determined by the participants, the setting, and the purpose of the transaction and differences between spoken and written discourse.

The students used models for their letter writing and were instructed in the organization and presentation of reports. The second report was more formal than the first. It included background research about their organization (from the library and tourist information centers) and an opinion poll (in which they asked people in town what they knew about the organization).

The students typed their written work on a computer. The use of wordprocessing facilities meant that revisions were easier, the students were more willing to make corrections and compare one another's work, and the final products were visually more attractive. The word-processing also deemphasised the role of the teacher. Although the teacher was present in both the computer room and the classroom, the students tended to ask one another questions in the computer room in both English and Japanese, whereas they tended to direct questions to the teacher in English in the classroom. 
The students wrote their letters and reports with various degrees of competence. They knew that the final product had to be well written in order for it to be sent to the interviewee and were therefore expecting rewriting to be necessary. The reports and letters were marked and returned to the students. Mistakes were categorized into grammar, style, and report-writing problems. Individual mistakes were circled but no alternatives provided. The students reworked their projects as many times as they felt necessary. Some students revised their projects only two or three times; others, insecure about their writing skills, asked their peers and teacher for continual feedback. When finally satisfied with both the covering letter and the report, they sent them to their interviewees.

\section{Oral Tasks}

The oral tasks included follow-up phone calls, a formal open-question interview and a less formal closed-question opinion poll. The follow-up phone calls were necessary when there was no response from the initial letter of request and the follow-up letter. The phone calls were simulated in the classroom. The actual call was made in the teacher's office with many of the students present to lend moral support to their fellow students. In the phone calls, the students identified themselves and their request. If the potential interviewee was unavailable, the student requested the name and contact number of another person associated with the club or organization.

To prepare for their interviews the students used role plays and group discussions. The preparation included a discussion of social and cultural information such as appropriate dress and time of meetings. It also included a discussion of the various types of questions and the phrasing and use of appropriate open and closed questions and lead-in statements. Students were also instructed in the use of various signs of encouragement and interruption techniques and learned how to start and conclude an interview in a variety of ways.

To prepare for the initial interview, the simplest approach to interviewing was taken. The students prepared a list of questions to enable them to be more fully in control of the interview event. The questions were discussed in class as to their appropriateness in style and content. Students listened to the questions of their peers and made individual judgments as to whether each question would be appropriate for their particular audience. Potential introductions, interruptions, encouragement, and concluding remarks were simulated and analyzed in a similar manner. The students used role-plays to practice their interviews.

The students conducted the interviews at prearranged times. The interviews were for the most part successful, although a few students experienced technical problems, for example, fast reverse erase, unclear or broken tapes. After the interview was completed, the students reported back on the succes- 
ses and failures of the interview. Because interviews were completed at different times, each student had an opportunity to participate in different roles (e.g., giving information, asking questions) in the classroom.

After completing the interviews, the students listened to their tapes and transcribed the key points that were later used to compose written descriptions of the interviewees and their occupations or, in the case of Module Two, descriptions of the club or society. Guidelines were again provided (e.g., how to transcribe tapes, differences between spoken and written language) and difficulties discussed.

The opinion polls provided a third type of speech event. For the polls the students prepared a list of 10 closed-answer questions about the organization they were researching (e.g., Have you ever heard about ...?) They approached 20 people outside the local shopping mall. This type of interview required the students to vary their style according to the participants and the setting. Lead-in statements and concluding statements were again simulated for this speech event.

\section{Problems with the Implementation of the Modules}

The most common problem was the length of time it took to receive a response. The responses by the interviewees to the student interview requests were generally positive; however, because some organizations met irregularly and others were extremely busy, many of the interviewees did not respond immediately to the initial request for interviews. Follow-up letters and phone calls were required, and in a few cases students had to request interviews from alternative sources. The slow responses did not pose serious difficulties. The library research and opinion poll sections in the Module Two reports allowed students to work independently on different aspects of their reports at their own pace.

Another major concern was the motivation of the students. A few of the students were discouraged when they failed to receive a response. Both the teacher and other students provided encouragement and suggestions to those students who had to write follow-up letters and/or make follow-up phone calls.

A third difficulty involved the pragmatic competence of the students. Grammatical and pragmatic competence levels were based on the results of a written test and oral interview conducted as part of an entrance test. Indicators of pragmatic competence included the use of strategic markers such as feedback markers (e.g., hmm), overlapping speech (e.g., A: Have you ever been to New Zealand // before? B: before), fillers (e.g., well, so); tags (e.g., isn't it? haven't you?), repair markers (e.g., I didn't quite get that) and so forth. The appropriate use of language in different settings is also part of pragmatic competence. 
Although all students had previously conducted interviews, they had done so in informal settings with friends, so the interviews had involved limited discoursal or strategic skills. The interviews in this project required the students to interact in a formal setting with different pragmatic requirements. Because the students chose a topic in which they had a personal interest, the projects were challenging but manageable. However, students who had spent less than a year in New Zealand reported in their two-minute class presentations that they had difficulties coping with the pragmatic requirements of an authentic interview, despite the fact that often their entrance tests showed that their grammatical competence was at a slightly more advanced level than that of their classmates. Students with lower-level language skills but greater pragmatic competence reported far fewer difficulties.

\section{Conclusions}

The success of this project can be demonstrated in a number of ways. First, student enthusiasm was high all through the project. In fact the students were more enthusiastic about sending their reports to their interviewee than submitting their reports to be graded by the teacher (usually important for Japanese learners).

Furthermore, the students used the skills gained in these tasks for activities outside the course in four ways. Many of the students used the word processing facilities on the computer to edit letters to request other types of information (enrollment forms for university and job application forms), whereas students from other classes asked for model letters to complete similar tasks. Other teachers at the college reported that students had transferred skills acquired in this course (e.g., lead-in statements) to activities in their classes. Also, in the following year one of the students who enrolled in a local university told me how helpful the report writing had been for writing research results in one of his university papers. Finally, several students joined the organizations they had researched. They attended meetings and social functions where they met new English-speaking friends.

As a result of a change in audience, students learned how to apply a set of skills to different types of "real" audiences. They did not view the tasks as repetitive. Rather, they were excited about the extending knowledge from one speech event to another. New audiences meant learning was reinforced in a positive way.

The project focused on the students' grammatical and pragmatic competence. The formal taped interviews and final written submissions were not only grammatically correct but also appropriately presented (e.g., in a semiformal style). Before they began this course, the students had few ideas about letter writing and reports and were largely unaware of differences between spoken and written discourse. For example, they had no knowledge of 
structural differences between the two forms of communication (e.g., sentence length and structure). During the course students condensed information in their spoken interviews into written reports by creating longer sentences, and by using more subordinate clauses, complex noun phrases, and more varied vocabulary. The Module Two interviews and reports contained many examples of how students were able to prepare questions in a formal yet friendly spoken style (e.g., I heard that the jazz society meets once a month-on a Tuesday) and then convert this information into formal written language (e.g., The jazz society meets the first Tuesday of each month).

Moreover, the projects helped the students learn about sociocultural aspects of life in New Zealand (e.g., the time of business closures, appropriate dress requirements) and develop strategic language skills (e.g., how to ask for clarification and interrupt). Their first interview had almost no overlapping speech or requests for clarification. By the time of their second interview all students had developed some of these strategic skills.

The modules provided an integrated approach to language learning as proposed by Brookes and Grundy (1990). The students gained knowledge through the interviews and the reports about the effect of audience on language use. Although the Module One letters proved useful as models for Module Two, the students were required to make small but communicatively significant changes because their audience had changed (e.g., they had to provide more background information about who they were). The task demonstrated the subtle effect audience can have on a speech event in a way that is extremely difficult realistically to create in a classroom setting.

\section{The Author}

Donna Starks is a lecturer in English at the University of Auckland, New Zealand. She has taught linguistics, and language and culture at various tertiary institutions in Canada and New Zealand. Her interests include intercultural communication, sociolinguistics, and sociocultural aspects of language learning.

\section{References}

Bardovi-Harlig, K., Hartford, B.A.S., Mahan-Taylor, R., Morgan, M.J., \& Reynolds, D.W. (1991). Developing pragmatic awareness in closing the conversation. ELT Journal, 45(1), 4-15.

Brookes, A., \& Grundy, P. (1990). Writing for study purposes. Cambridge: Cambridge University Press.

Crawford, J. (1990). How authentic is the language in our classrooms? Prospect, 6(1), 47-54.

Vincent, S. (1990). Motivating the advanced learner in developing writing skills: A project. ELT Journal, 44(4), 272-278. 